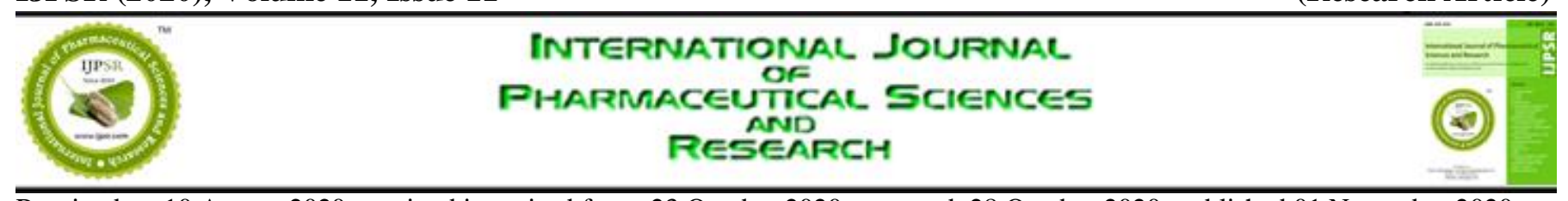

Received on 10 August 2020; received in revised form, 23 October 2020; accepted, 28 October 2020; published 01 November 2020

\title{
ANTIBIOTICS SUSCEPTIBILITY IN CHRONIC SUPPURATIVE OTITIS MEDIA (CSOM) AT THE SECONDARY CARE HOSPITAL IN NORTH INDIA
}

\author{
Anuj Kumar Singh ${ }^{1}$, Shashi Alok ${ }^{2}$ and Amita Verma *3
}

Department of Otorhinolaryngology and Head Neck Surgery ${ }^{1}$, ESIC Hospital, Varanasi - 221002, Uttar Pradesh, India.

Institute of Pharmacy ${ }^{2}$, Bundelkhand University, Jhansi - 284128, Uttar Pradesh, India.

Bioorganic \& Medicinal Chemistry Research Laboratory ${ }^{3}$, Department of Pharmaceutical Sciences, Sam Higginbottom University of Agriculture, Technology \& Sciences, Allahabad - 211007, Uttar Pradesh, India.

Keywords:

Chronic suppurative otitis media, Antibiotic susceptibility, MRSA, MSSA, Pseudomonas

Correspondence to Author:

Prof. (Dr.) Amita Verma

Professor,

Bioorganic \& Medicinal Chemistry

Research Laboratory, Department of

Pharmaceutical Sciences, Sam

Higginbottom University of

Agriculture, Technology \& Sciences,

Allahabad - 211007, Uttar Pradesh, India.

E-mail: amitaverma.dr@gmail.com

\begin{abstract}
Background: Chronic suppurative otitis media (CSOM) is defined as a persistent infection of the middle ear cleft with a perforated tympanic membrane and draining exudate for more than 6weeks. Information about the organism responsible for COSM and their antibiotic susceptibility is important for effective treatment. Material and Methods: A prospective cross-sectional study was conducted on 85 patients; the middle ear discharge sample was collected under strict aseptic conditions and antibiotic susceptibility done as per Clinical Laboratory Standards Institute guidelines. Result: 85 ear swabs were collected, and 89 bacterial isolates were identified, of which $72.94 \%$ sample with mono-microbial growth, $16.47 \%$ with polymicrobial growth, $9.41 \%$ show no growth, and the rest $1.17 \%$ was a contaminant. Among 89 isolates, $39.33 \%$ were Gram-positive, while $60.67 \%$ were Gram-negative bacteria. The most common isolates were Pseudomonas species $40.45 \%$ followed by methicillin sensitive staphylococcus aureus (MSSA) $38.20 \%$ and others $21.35 \%$. Pseudomonas species showed $100 \%$ susceptible to colistin, linezolid, imipenem, amikacin (97\%); ciprofloxacin (92\%); gentamicin (95\%); Ceftriaxone (83\%); meropenem (93\%); Netilmicin (98\%) and Sulfamethoxazole and Trimethoprim (SXT) (90\%). Proteusspecies was 100\% susceptible to amikacin, ciprofloxacin, Imipenem, meropenem, netilmicin; ampicillin (71\%); amoxicillinclavulanic acid (85\%); ceftriaxone (85\%); gentamicin $(85 \%)$ and SX (85\%).Among Gram-positive bacteria, MSSA was $100 \%$ susceptible to meropenem and Imipenem, amikacin (97\%); gentamicin (81\%); amoxicillin-clavulanic acid (91\%); linezolid (92\%); Netilmicin (94\%); Vancomycin (91\%); Colistin (97\%) and SXT (41\%). Conclusion: Pseudomonas and MSSA were the principal bacterial isolate responsible for causing CSOM.
\end{abstract}

INTRODUCTION: Chronic suppurative otitis media (CSOM) is defined as a persistent infection of the middle ear with a perforated tympanic membrane and draining exudate for more than 6 weeks $^{1,2}$.

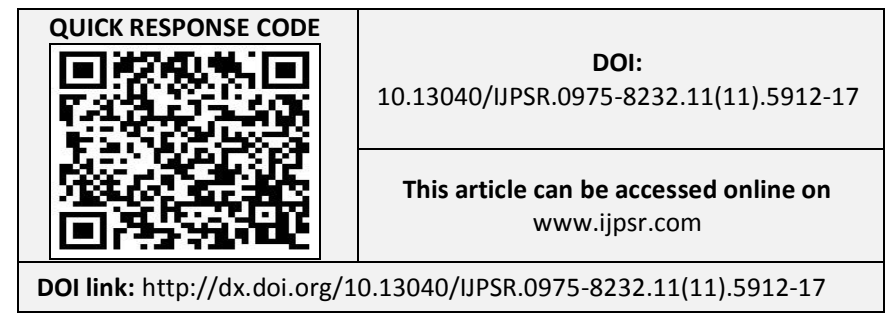

Thirty-one million people developed CSOM across the globe every year and with prevalence of disease is as much as three times higher in developing countries than western developed world around the world. The World Health Organization (WHO) has categorized CSOM as neglected tropical diseases and is more common in low socio-economical status $^{3}$.

CSOM usually occurs due to poor and inadequate management of acute otitis media. The etiology and antimicrobial resistance patterns of CSOM 
infection are different in different geographical areas, and the population studied. CSOM is predominantly caused by Pseudomonas aeruginosa, Escherichia coli, S. aureus, Streptococcus pyogenes, Proteus mirabilis, Klebsiella species among aerobic bacteria. However, Bacteroides, Pepto streptococcus, Propionibacterium are common anaerobic bacteria 4, 5. In India, studies were conducted at various parts of the country to establish common pathogen and antibiotic susceptibility. Some studies concluded as Pseudomonas species other shows Staphylococcus species ${ }^{6,7}$ as the most common aerobic bacterial isolate involved in CSOM ${ }^{8,9,10,11}$. Some show polymicrobial pathogens. Anaerobic pathogens like Peptostreptococcus species, Bacteroides species and Peptococcus species involved in $10-11 \%$ cases of CSOM ${ }^{9}$. The most common fungal agent to be Aspergillus species, which was nearly $83 \%$ of all fungal causes of CSOM and the second most common cause was Candida species ${ }^{12}$.

Thus, information about the organism responsible for COSM and their antibiotic susceptibility pattern is important for effective treatment. Therefore, the aim of this study was to determine the bacterial profile and their antibiotic susceptibility patterns in COSM from patients attending the ENT clinic of the hospital.

\section{MATERIALS AND METHODS:}

Study Design and Setting: A cross-sectional study was conducted at the ENT department of the secondary care hospital in North India. A total of 85 patients with unilateral or bilateral active chronic otitis media were studied. The study participants were enrolled consecutively using a convenience sampling technique. All study participants had perforated tympanic membranes with active purulent discharge. The detailed information regarding age, sex, duration of discharge, and the antibiotic is taken prior to pus collection was collected from each study participant using a structured questionnaire in the ENT clinic. Whereas ear discharge of less than 6 weeks duration, otitis externa, and patient taking topical/systemic antibiotic within 7 days before pus collection were excluded.

Sample Collection: Middle ear discharge sample was collected at ENT clinic under strict aseptic conditions using single-use sterile cotton-tipped culture swabs, after proper cleaning the external auditory canal using povidone-iodine and spirit swab for each ear to prevent contaminants. The swabs were transported to the microbiology laboratory in the department of pathology of the same hospital for culture and antibiotic susceptibility testing.

Culture and Identification: Swab was directly used for inoculating on 5\% sheep blood agar, MacConkey agar. The blood and MacConkey agar plates were incubated aerobically were incubated at $37{ }^{\circ} \mathrm{C}$ for $24-48 \mathrm{~h}$. The isolates were identified by colony morphology, Gram stain and standard microbiological tests like oxidase test, coagulase test and biochemical tests like triple sugar iron test, indole test, citrate utilization test, and urease test ${ }^{13}$.

Antibiotic susceptibility tests were performed using a modified Kirby-Bauer disc diffusion method following the Clinical Laboratory Standards Institute guidelines.

Data Analysis and Interpretation: Data were entered and analyzed using SPSS version 20 software. Results were presented through graphs and tables. The statistical significance of association was measured by using the Chi-square test. A p-value $<0.05$ was considered as statistically significant.

RESULTS: A total of 85 patients participated in the study. Out of which $57(67.05 \%)$ were male, and $28(32.94 \%)$ were female. The mean age of the study participant was 23 years and ranging from 4 to 68 years. Thirty-nine $(45.88 \%)$ of them were aged below 20 years, 37(43.57\%) were between 21- 40 years, 7 (8.24\%) were between $41-60$ years, and $2(2.35 \%)$ were above 61 years. $29(34.11 \%)$ patients had bilateral disease, $56(65.88 \%)$ of the patients had unilateral CSOM. Left ear disease is seen in $33(58.93 \%)$ patients.

Of the 85 ear swabs, 89 bacterial isolates were identified. Of which $62(72.94 \%)$ sample with mono-microbial growth, $14 \quad(16.47 \%)$ with polymicrobial growth, $8(9.41 \%)$ show no growth and remaining $1(1.17 \%)$ shows contaminants. Among 89 isolates, 35 (39.33\%) were Grampositive bacteria, while $54(60.67 \%)$ were Gramnegative bacteria. The most common isolates were Pseudomonas species $(36 ; 40.45 \%)$, followed by 
Methicillin sensitive Staphylococcus aureus MSSA (34; 38.20\%), Proteus species $(7 ; 7.87 \%)$, Klebsiella species $(3 ; 3.37 \%)$, Enterobacter species (3; $3.37 \%)$, E. coli $(3 ; 3.37 \%)$, Actinobacteria species $(2 ; 2.25 \%)$ and Methicillin resistant Staphylococcus aureus (MRSA) $(1 ; 1.12 \%)$.

Mixed cultures $(14 ; 16.47 \%)$ seen in equal percentage in both adult and child population, with a combination of Pseudomonas species and MSSA in 50\% (7/14); Enterobacter species and MSSA $14.29 \%$ (2/14); Acinetobacter species / E. colil Proteus species and MSSA 7.14\% (each 1/14); Proteus species and Pseudomonas species 7.14\% (1/14) and Acinetobacter species and Enterobacter species $7.14 \%$ (1/14). Antibiotic susceptibility patterns of most isolated Gram-negative and Grampositive bacteria, respectively. Pseudomonas species showed $100 \%$ susceptible to colistin, linezolid, imipenem; amikacin (97\%); ciprofloxacin (92\%); gentamicin (95\%); Ceftriaxone (83\%); meropenem
(93\%); Netilmicin (98\%) and SXT (90\%). Proteus species were $100 \%$ susceptible to amikacin, ciprofloxacin, Imipenem, meropenem, netilmicin; ampicillin (71\%); amoxicillin-clavulanic acid (85\%); ceftriaxone (85\%); gentamicin (85\%) and Sulfamethoxazole and Trimethoprim SXT (85\%).

Among Gram-positive bacteria, MSSA was $100 \%$ susceptible to meropenem and Imipenem; amikacin (97\%); gentamicin (81\%); amoxicillin-clavulanic acid (91\%); linezolid (92\%); Netilmicin (94\%); Vancomycin (91\%); Colistin (97\%) and SXT (41\%). MRSA showed $100 \%$ susceptibility to gentamicin, netilmicin and vancomycin.

The resistance pattern among the gram-positive isolates was, MRSA was $100 \%$ resistant to ampicillin, linezolid, and SXT. MSSA was found resistant to ampicillin (65\%) and SXT (59\%) Fig. 1 and Table 1.
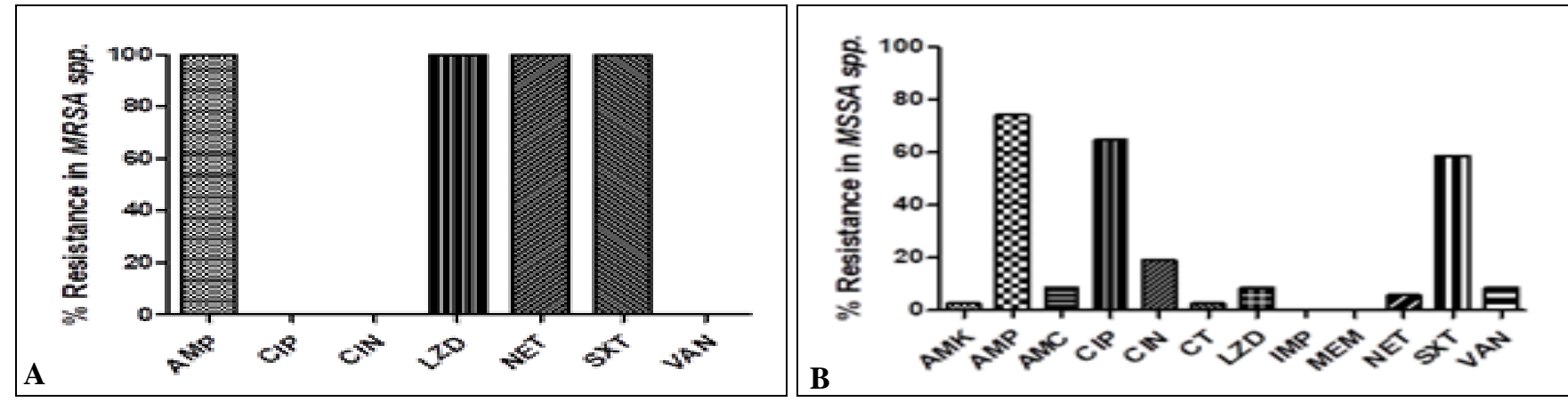

FIG. 1: ANTIBIOTICS RESISTANCE PATTERN IN MRSA SPP (A) MSSA SPP (B)

TABLE 1: ANTIMICROBIAL RESISTANCE IN GRAM-POSITIVE ORGANISM

\begin{tabular}{|c|c|c|c|c|c|c|c|c|c|c|c|c|c|}
\hline \multirow[t]{2}{*}{ Isolates } & \multicolumn{13}{|c|}{ Antibiotic Resistance (Gram-Positive) } \\
\hline & $\begin{array}{l}\text { AMK } \\
\text { n (\%) }\end{array}$ & $\begin{array}{l}\text { AMP } \\
\text { n }(\%)\end{array}$ & $\begin{array}{l}\text { AMC } \\
\text { n (\%) }\end{array}$ & $\begin{array}{c}\text { CIP } \\
\text { n (\%) }\end{array}$ & $\begin{array}{l}\text { CRO } \\
\text { n }(\%) \\
\end{array}$ & $\begin{array}{c}\text { CIN } \\
\text { n }(\%)\end{array}$ & $\begin{array}{c}\text { CT } \\
\text { n }(\%)\end{array}$ & $\begin{array}{c}\text { LZD } \\
\text { n (\%) }\end{array}$ & $\begin{array}{c}\text { IMP } \\
\text { n (\%) }\end{array}$ & $\begin{array}{l}\text { MEM } \\
\text { n }(\%)\end{array}$ & $\begin{array}{l}\text { NET } \\
\text { n }(\%)\end{array}$ & $\begin{array}{c}\text { SXT } \\
\text { n }(\%)\end{array}$ & $\begin{array}{l}\text { VAN } \\
\text { n }(\%) \\
\end{array}$ \\
\hline $\begin{array}{l}\text { MRSA (n=1) } \\
\text { Resistance (R) }\end{array}$ & ND & $1(100)$ & ND & 0 & ND & 0 & ND & $1(100)$ & ND & ND & $1(100)$ & $1(100)$ & 0 \\
\hline $\begin{array}{l}\text { MSSA }(n=34) \\
\text { Resistance (R) }\end{array}$ & $1(2.94)$ & 23(74.19) & $3(8.82)$ & $22(64.71)$ & ND & $6(19.35)$ & $1(2.94)$ & $3(8.82)$ & 0 & 0 & $2(5.88)$ & $20(58.82)$ & $3(8.82)$ \\
\hline
\end{tabular}

In gram-negative isolates, Pseudomonas species found resistance to Ampicillin (100\%), amoxicillinclavulanic acid (97\%), ceftriaxone (47\%) and SXT (28\%); Proteus species found resistance to Colistin (86\%) and ampicillin (29\%); Klebsiella species found resistance to Colistin (100\%), ampicillin (67\%) and SXT (33\%); Enterobacter species spp. and Acinetobacter species spp. found $100 \%$ resistant to ampicillin; $E$. coli was $33 \%$ resistant to amoxicillin-clavulanic acid, ciprofloxacin, and ceftriaxone. All the resistance patterns are represented in Fig. 2 and Table 2.
DISCUSSION: CSOM is defined as chronic otorrhea of more than 6 weeks duration through a perforated tympanic membrane. CSOM is a disease of multiple etiologies and is well known for persistence and recurrence in spite of treatment. The disease has irreversible sequelae and leads to serious intra and extracranial complications due to the proximity of various important structures viz. facial nerve, auditory labyrinth, lateral sinus, and middle and posterior fossa dura. CSOM is mainly classified as attico-antral (squamous COM) and tubo-tympanic (mucosal) type. According to the 
world health organization (WHO) the prevalence of CSOM in Asian countries is about $4 \%$ which is much more than the developed western world ${ }^{4}$. The indiscriminate use of antimicrobials in Asian countries lead to multiple drugs resistance among the infective organisms leading to treatment challenges. There are no gender predilections though most surveys were done on children, CSOM can affect both the children as well the adults, as presented in this study. Many researchers had addressed the issue of finding the common isolates and their sensitivity pattern among the antimicrobials in line with developing the treatment protocols in different regions of the world.
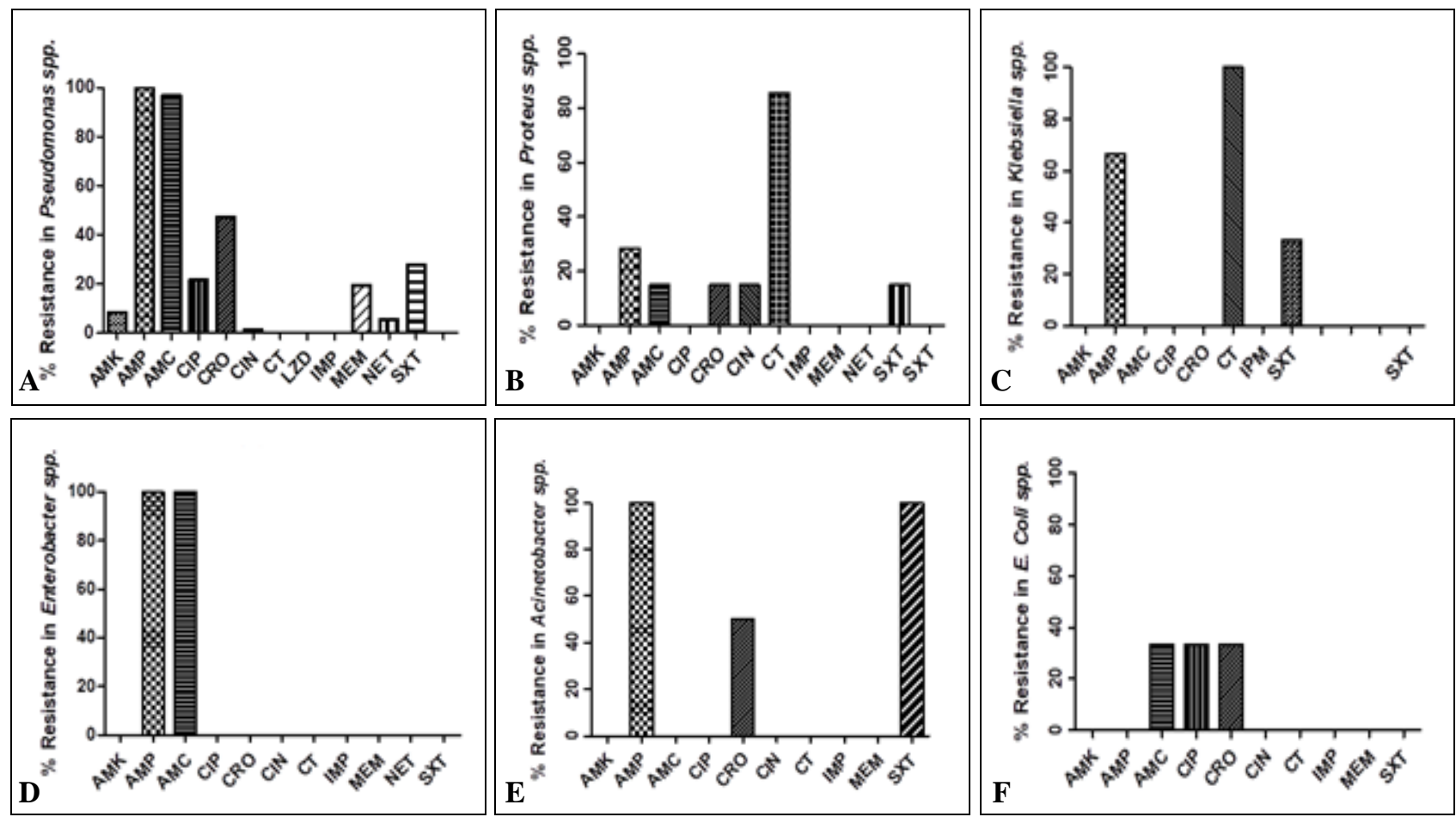

FIG. 2: ANTIBIOTICS RESISTANCE PATTERN IN (A) PSEUDOMONAS (B) PROTEUS (C) KLEBSIELLA (D) ENTEROBACTER (E) ACINETOBACTER (F) E. COLI

TABLE 2: ANTIMICROBIAL RESISTANCE IN GRAM-NEGATIVE ORGANISM

\begin{tabular}{|c|c|c|c|c|c|c|c|c|c|c|c|c|c|}
\hline \multirow[t]{2}{*}{ Isolates } & \multicolumn{13}{|c|}{ Antibiotic Resistance (Gram Negative) } \\
\hline & $\begin{array}{l}\text { AMK } \\
\text { n }(\%)\end{array}$ & $\begin{array}{l}\text { AMP } \\
\mathbf{n}(\%)\end{array}$ & $\begin{array}{l}\text { AMC } \\
\text { n }(\%)\end{array}$ & $\begin{array}{c}\text { CIP } \\
\text { n }(\%)\end{array}$ & $\begin{array}{l}\text { CRO } \\
\text { n }(\%)\end{array}$ & $\begin{array}{c}\text { CIN } \\
\text { n }(\%)\end{array}$ & $\begin{array}{c}\text { CT } \\
\text { n }(\%)\end{array}$ & $\begin{array}{l}\text { LZD } \\
\text { n }(\%)\end{array}$ & $\begin{array}{l}\text { IMP } \\
\text { n }(\%)\end{array}$ & $\begin{array}{l}\text { MEM } \\
\text { n }(\%)\end{array}$ & $\begin{array}{l}\text { NET } \\
\mathrm{n}(\%)\end{array}$ & $\begin{array}{c}\text { SXT } \\
\text { n }(\%)\end{array}$ & $\begin{array}{l}\text { VAN } \\
\text { n }(\%)\end{array}$ \\
\hline $\begin{array}{l}\text { Pseudomonas } \\
\text { spp. }(\mathrm{n}=36)\end{array}$ & $3(8.33)$ & $36(100)$ & $35(96.7)$ & $8(21.74)$ & $17(47.22)$ & $5(1.39)$ & $0(0)$ & $0(0)$ & $0(0)$ & $7(19.44)$ & $2(5.55)$ & $10(27.78)$ & ND \\
\hline Resistance (R) & & & & & & & & & & & & & \\
\hline $\begin{array}{l}\text { Proteus spp. }(\mathrm{n}=7) \\
\text { Resistance }(\mathrm{R})\end{array}$ & 0 & $2(28.57)$ & $1(14.9)$ & 0 & $1(14.9)$ & 1(14.9) & $6(85.71)$ & ND & 0 & 0 & 0 & $1(14.9)$ & ND \\
\hline $\begin{array}{l}\text { Klebsiella spp. }(\mathrm{n}=3) \\
\text { Resistance }(\mathrm{R})\end{array}$ & 0 & $2(66.66)$ & 0 & 0 & 0 & ND & $3(100)$ & ND & 0 & ND & ND & 1(33.33) & ND \\
\hline $\begin{array}{c}\text { Enterobacter spp. } \\
\quad(\mathrm{n}=3)\end{array}$ & 0 & $3(100)$ & 3 & 0 & 0 & 0 & 0 & ND & 0 & 0 & 0 & 0 & ND \\
\hline $\begin{array}{c}\text { Resistance }(\mathrm{R}) \\
\text { Acinetobacter spp. } \\
(\mathrm{n}=2)\end{array}$ & 0 & $2(100)$ & 0 & 0 & $1(50)$ & 0 & 0 & ND & 0 & 0 & ND & $2(100)$ & ND \\
\hline $\begin{array}{c}\text { Resistance }(\mathrm{R}) \\
\text { E. coli }(\mathrm{n}=3) \\
\text { Resistance }(\mathrm{R})\end{array}$ & 0 & 0 & 1(33.33) & $1(33.33)$ & 1(33.33) & 0 & 0 & ND & 0 & 0 & ND & 0 & ND \\
\hline
\end{tabular}

In the present study $62(72.94 \%)$ sample with mono-microbial growth, $14 \quad(16.47 \%)$ with polymicrobial growth, $8(9.41 \%)$ show no growth, and the remaining $1(1.17 \%)$ shows contaminants. Our study is correlated with Gopichand WR et al., ${ }^{11}$ and Tadesse et al., ${ }^{14}$ in which most isolates are pure culture rather than the mixed one.
The aerobic bacterial isolates in our study are Pseudomonas species (40.45\%), followed by MSSA (38.20\%), Proteus species (7.87\%), Klebsiella species (3.37\%), Enterobacter species (3.37\%), E. coli $(3.37 \%)$, Actinobacteria species $(2.25 \%)$ and $\operatorname{MRSA}(1.12 \%)$. 
In our study, the most common isolate was Pseudomonas species, and it was similar to other studies, where also Pseudomonas species predominantly found in 48-98\% of patients $15,16,17$. Imipenem was $100 \%$ sensitive to all gram-negative isolates, consistent with the study of Rahim et al. ${ }^{18}$ Amikacin was $100 \%$ sensitive in gram-negative isolates except $8.33 \%$ of Pseudomonas spp. and $2.94 \%$ samples of MSSA shows resistance to amikacin; this study is also at par of observation done by Maji et al., SXT was most effective antibiotic against MRSA as shown by Park et al., ${ }^{19}$ in contrary to our study shows $100 \%$ resistance of MRSA spp. for SXT though it was not statistically significant.

In general, our result has demonstrated that amikacin, ciprofloxacin, gentamicin, colistin, linezolid, imipenem and ceftriaxone are very sensitive to gram-negative organism. Among Gram-positive bacteria meropenem, Imipenem, amikacin, gentamicin, amoxicillin-clavulanic acid, linezolid, Netilmicin, Vancomycin, and Colistin are had bactericidal effects in the majority.

The small sample size of this study may restrict the value of our finding, the frequently used antimicrobials in CSOM like penicillin developed high levels of resistance among the organisms like Pseudomonas and MSSA leading to treatment failures.

CONCLUSION: CSOM still one of the most common causes of hearing impairment in India and the patients attending the ENT clinics have most frequent complaints of ear discharge with hard of hearing shows the morbidity among the population due to CSOM. Pseudomonas species and MSSA were the principal bacterial isolate responsible for causing CSOM in this study through the most common organism was Pseudomonas species. The effective treatment, as per the cultural sensitivity of CSOM, can reduce the morbidity considerably.

ACKNOWLEDGEMENT: We would like to thank the study participants and the department of microbiology for conducting the study.

CONFLICTS OF INTEREST: Authors declare no conflict of interest.

FUNDING: NA

\section{REFERENCES:}

1. Mittal R, Lisi CV, Gerring R, Mittal J and Mathee K: Current concepts in the pathogenesis and treatment of chronic suppurative otitis media. J Med Microbiol 2015; 64(10): 1103-16.

2. Monasta L, Ronfani L, Marchetti F, Montico M and Brumatti LV: Burden of disease caused by otitis media: systematic review and global estimates. PLOS ONE 2012; 7(4): e36226.

3. Li MG, Hotez PJ, Vrabec JT and Donovan DT: Is chronic suppurative otitis media a neglected tropical disease? PLOSN egl Trop Dis 2015; 9(3): e0003485.

4. Sattar A, Alamgir A, Hussain Z, Sarfraz S, Nasir J and Alam B: Bacterial spectrum and their sensitivity pattern in patients of chronic suppurative otitis media. J Coll Physicians Surg Pak 2012; 22: 128-29.

5. Liu YH: Bacteriological examination of inflamed epidermal cysts: A survey between 2008 and 2009 at a hospital in Southern Taiwan. Dermatologica Sin 2010. doi:10.1016/S1027-8117(10)60022-5.

6. Poorey VK and Iyer Arti: Study of bacterial flora in CSOM and its clinical significance. Indian Journal of Otolaryngology and Head and Neck Surgery2002; 54: 91 95.

7. Maji PK, Chatterjee TK, Chatterjee S, Chakrabarty J and Mukhopadhyay BB: The investigation of bacteriology of chronic suppurative otitis media in patients attending a tertiary care hospital with special emphasis on seasonal variation. Indian J Otolaryngol Head and Neck Surg 2007; 59: $128-31$.

8. Ettehad GH, Refahi S, Nammati A, Pirzadeh A and Daryani A: Microbial and antimicrobial susceptibility pattern from patients with Chronic Otitis Media in Arebil. International Journal of Tropical Medicine 2006; 1(2): 6265 .

9. Nikakhlagh S, Khosrani AD, Falipour A Safarzadeh M and Rahidi N: Microbiological finding in Patients with Chronic Suppurative Otitis Media. J Med Sci 2008; 8(5): 503-506.

10. Rao BN and Reddy MS: Chronic suppurative otitis mediaA prospective study. Indian Journal of Otolaryngology and Head and Neck Surgery 1994; 3(2): 72-77.

11. Gopichand WR, Madhusudan BV and Tukaram KV: Bacteriological Profile of Chronic Suppurative Otitis Media. Int $\mathbf{J}$ of current Microbiology and Applied Sciences 2015; 4(6): 41-47.

12. Mittal A, Mann SBS, Talwar P, Mehra YN and Panda N: Secondary Fungal infections in chronic suppurative otitis media. Indian J Otolaryngol Head and Neck surg 1997; 49(2): 112-16.

13. Forbes BA, Sahm DF and Weissfeld AS: Bailey and Scott's diagnostic microbiology. Mosby, 10 ${ }^{\text {th }}$ edition 1998.

14. Tadesse B, Shimelis T and Worku M: Bacterial Profile and antimicrobial susceptibility of otitis media among pediatric patients in Hawassa, Southern Ethopia: crosssectional study. BMC Pediatrics 2019; 19: 398-05.

15. Loy AH, Tan AL and Lu PK: Microbiology of chronic suppurative otitis media in Singapore. Singapore Med J 2002; 43(6): 296-99.

16. Hiremath SL, Kanta RC, Yeshwanathrao M and Vasantha KCM: Aerobic bacterial isolates of CSOM and their antibiotic sensitivity pattern. The Indian Practitioner 2001; 54(7): 486-89.

17. Kumar A, Jayachandran L and Kumar S: Antimicrobial susceptibility pattern in chronic suppurative otitis media patient in a tertiary care hospital. Value Health 2016; 19(7): 845-46. 
18. Rahim E, Gul AA, Ahmed S and Ali L: Frequency of Pseudomonas aeruginosa in patients and its sensitivity to various antibiotics. Professional Med J 2007; 14(3): 41115 .
19. Park KM, Jung HM, Kang JH, Woo JS, Lee HM and Jung HJ: The change of MRSA infections in chronic suppurative otitis media. Otolaryngology-Head and Neck Surg 2008; 8(5): 503-06

How to cite this article:

Singh AK, Alok S and Verma A: Antibiotics susceptibility in Chronic Suppurative Otitis Media (CSOM) at the secondary care hospital in North India. Int J Pharm Sci \& Res 2020; 11(11): 5912-17. doi: 10.13040/IJPSR.0975-8232.11(11).5912-17.

All @ 2013 are reserved by the International Journal of Pharmaceutical Sciences and Research. This Journal licensed under a Creative Commons Attribution-NonCommercial-ShareAlike 3.0 Unported License.

This article can be downloaded to Android OS based mobile. Scan QR Code using Code/Bar Scanner from your mobile. (Scanners are available on Google Playstore) 